region of the stomach more frequently than we expected, and in several cases the instrument has passed through the stoma and good views have been obtained of the efferent loop jejunum. However, our present impression is that in this group of cases the gastroscope may prove to be more reliable than the gastrocamera.

2. Pyloric Stenosis.-Repeated washouts are singularly ineffective in cleaning the stomach, and photography is often spoiled by food residues. Nevertheless positive evidence of antral carcinoma has been obtained in several cases, and in two cases the stenosis has been shown to be associated with benign gastric ulcer remote from the pylorus.

3. The Spastic and Irritable Antrum.--Radiological evidence is often insecure in these cases, and photography has been valuable. By virtue of the great flexibility of the gastro-camera it is usually possible to obtain better views of the lesser curve of the antrum than can be achieved at gastroscopy. Some of these dubious antra appear to be entirely normal. In others a benign ulcer has been visible on or distal to the angulus. None so far has revealed carcinoma.

4. "X-ray Negative Dyspepsia."-The ease and simplicity of gastrophotography have led us to employ this method frequently in these cases where we might have hesitated to carry out gastroscopy.

In our first 100 cases five gastric ulcers, invisible at bariummeal examination, were shown.

5. The Suspicious Gastric Ulcer.-Short of histological examination there is no method of investigation (including laparotomy) which can guarantee to distinguish between benign and malignant gastric ulcer. Nevertheless with experience endoscopic mistakes are few, and, provided that good photographs of the ulcer and the surroundings can be obtained, diagnostic accuracy compares favourably with radiological assessment and also with surgical opinion at laparotomy.
In elderly patients, who should be spared extensive gastrectomy whenever possible, the information gained by gastrophotography has often been most valuable.

6. Gastroduodenal Haemorrhage.-In the early diagnosis of the source of haemorrhage the delay in film-processing makes the gastro-camera inferior to the gastroscope.

\section{Conclusions and Summary}

The Olympus gastro-camera is an instrument of practical value in the diagnosis of gastric disease.

The safety and relative simplicity of its use and the ease with which the technique can be learned, as compared with gastroscopy, suggest that its employment in this country should be extended.

The instrument is described and the technique of its use outlined.

Its application to specific problems of diagnosis is discussed.

Those who do acquire the instrument should use it freely both in in-patient and in out-patient work.

I wish to record with gratitude my thanks to Professor Yawara Yoshitoshi for facilities extended to me to work in his department at the University of Tokyo and to Dr. Hirohumi Niwa, Dr. Taddeo Sakita, and their colleagues for personal help both there and at the National Cancer Centre.

I also acknowledge with thanks the receipt of a generous grant from the Wellcome Trust towards the cost of the Colour Plates.

\section{BIBLIOGRAPHY}

Chrysopathis, P. (1963). Surgery, 54, 292. Hara, Y., Ogoshi, K., Karasawa, K., Osawa, G., Yokoyama, Y., and

Uji, T., Shirotokoro, T., and Hayashida, T. (1953). Tokyo med. f., 61, 135.

\title{
Effect of Periodic Dialysis on the Peripheral Neuropathy of End-stage Renal Failure
}

\author{
F. I. D. KONOTEY-AHULU,* M.B., M.R.C.P., M.R.C.P.GLASG., D.T.M.\&H. ; ROSEMARIE BAILLOD,* M.B., B.S. ; \\ CHRISTINA M. COMTY,* M.B., B.SC., M.R.C.P.ED.; J. R. HERON,* M.B., M.R.C.P.ED. ; \\ STANLEY SHALDON,* M.A., M.D., M.R.C.P. ; P. K. THOMAS,* M.D., B.SC., M.R.C.P.
}

Brit. med. F., 1965, 2, 1212-1215

Although in performing periodic haemodialysis the aim is to achieve the fullest possible degree of rehabilitation, this may be hindered by peripheral neuropathy (Murray et al., 1964). This syndrome was recognized by Osler (1892), and recently has been given much prominence by the advent of chronic haemodialysis (Hegstrom et al., 1961, 1962 ; Locke et al., 1961 ; Asbury et al., 1963 ; Funck-Brentano and Vantelon, 1963 ; Lindholm et al., 1963, Shaldon et al., 1963 ; Barber et al., 1963 ; Gonzales et al., 1963 ; Versaci et al., 1964 ; Shaldon, 1965), particularly as in some patients the neuropathy is brought to light (Hegstrom et al., 1961 ; Burnell et al., 1963) or made worse in the early period of a chronic dialysis programme (Hegstrom et al., 1962 ; Burnell et al., 1963).

This communication describes observations on the clinical features of uraemic neuropathy occurring in 20 patients

\footnotetext{
- From the Renal Unit and Department of Neurology, The Royal Free
} Hospital, London. currently receiving regular dialysis therapy, together with studies of nerve conduction.

\section{Material}

Twenty patients, 13 men and 7 women (age range 17 to 57 years), with end-stage renal failure were studied (Table I). Renal failure was due to chronic glomerulonephritis, chronic pyelonephritis or polycystic kidneys. Patients with renal failure due to multiple systemic diseases such as diabetes mellitus, amyloidosis, or systemic lupus erythematosus were excluded. Fifty per cent. of patients had malignant hypertension at the start of treatment. All patients were suffering from clinical end-stage renal failure, with marked biochemical impairmen of renal function (Table II). The average pretreatment blood urea was $394 \mathrm{mg} . / 100 \mathrm{ml}$. (262-756 mg. $/ 100 \mathrm{ml}$.$) and$ creatinine clearances were $5 \mathrm{ml}$./min. or less. 
Table I.-Clinical Data of Patients on Chronic Dialysis Programme

\begin{tabular}{|c|c|c|c|}
\hline Case No. & Age & Sex & Diagnosis \\
\hline $\begin{array}{l}1 \\
2\end{array}$ & $\begin{array}{l}34 \\
33\end{array}$ & $\begin{array}{l}M \\
M\end{array}$ & $\begin{array}{l}\text { Chronic glomerulonephritis } \\
\text { Chronic glomerulonephritis. Malignant } \\
\text { hypertension }\end{array}$ \\
\hline $\begin{array}{l}3 \\
4\end{array}$ & $\begin{array}{l}24 \\
34\end{array}$ & $\underset{\mathbf{F}}{\mathbf{M}}$ & $\begin{array}{l}\text { Chronic pyelonephritis." Malignant } \\
\text { hypertension }\end{array}$ \\
\hline $\begin{array}{l}5 \\
6\end{array}$ & $\begin{array}{l}42 \\
24\end{array}$ & $\begin{array}{l}\mathbf{M} \\
\mathbf{M}\end{array}$ & $\begin{array}{l}\text { Polycystic kidneys } \\
\text { Chronic glomerulonephritis. Malignant } \\
\text { hypertension }\end{array}$ \\
\hline $\begin{array}{l}7 \\
8 \\
9\end{array}$ & $\begin{array}{l}38 \\
31 \\
36\end{array}$ & $\begin{array}{l}M \\
M \\
M\end{array}$ & $\begin{array}{l}\text { Chronic glomerulonephritis } \\
\text { Chronic pyelonephritis. Primary gout } \\
\text { Chronic glomerulonephritis. Malignant } \\
\text { hypertension }\end{array}$ \\
\hline $\begin{array}{l}10 \\
11 \\
12 \\
13\end{array}$ & $\begin{array}{l}25 \\
19 \\
29 \\
27\end{array}$ & $\begin{array}{l}\mathbf{M} \\
\mathbf{M} \\
\mathbf{M}\end{array}$ & $\begin{array}{l}\text { Chronic "pyelonephritis } \\
\text { Ch" " } \\
\text { hypertension glomerulonephritis. Malignant }\end{array}$ \\
\hline $\begin{array}{l}14 \\
15 \\
16\end{array}$ & $\begin{array}{l}26 \\
38 \\
36\end{array}$ & $\underset{\mathbf{F}}{\mathbf{M}}$ & $\begin{array}{l}\text { Chronic" pyeloneph"itis } \\
\text { Chronic glomerulonephritis. Malignant } \\
\text { hypertension }\end{array}$ \\
\hline $\begin{array}{l}17 \\
18 \\
19 \\
20\end{array}$ & $\begin{array}{l}32 \\
57 \\
18 \\
40\end{array}$ & $\begin{array}{l}\mathbf{F} \\
\mathbf{F} \\
\mathbf{F}\end{array}$ & $\begin{array}{l}\text { Polycystic kidneys" } \\
\text { Chronic pylonephritis } \\
\text {," },\end{array}$ \\
\hline
\end{tabular}

TABle II.-Clinical Peripheral Neuropathy and Biochemical Data of Patients on Chronic Dialysis Programme

\begin{tabular}{|c|c|c|c|c|c|}
\hline \multirow{2}{*}{$\begin{array}{l}\text { Case } \\
\text { No. }\end{array}$} & \multirow{2}{*}{$\begin{array}{l}\text { No. of } \\
\text { Months of } \\
\text { Dialysis } \\
\text { Therapy }\end{array}$} & \multicolumn{2}{|c|}{ Before Therapy } & \multicolumn{2}{|c|}{ Clinical Peripheral Neuropathy } \\
\hline & & $\begin{array}{c}\text { Plasma } \\
\text { Urea }\end{array}$ & $\begin{array}{l}\text { Creatinine } \\
\text { Clearance }\end{array}$ & Sensory & Motor \\
\hline $\begin{array}{r}1 \\
2 \\
3 \\
4 \\
5 \\
6 \\
7 \\
8 \\
9 \\
10 \\
11 \\
12 \\
13 \\
14 \\
15 \\
16 \\
17 \\
18 \\
19 \\
20\end{array}$ & $\begin{aligned} 21 \\
16 \\
16 \\
19 \\
16 \\
27 \\
12 \\
11 \\
7 \\
7 \\
7 \\
5 \\
5 \\
3 \\
3 \\
3 \\
2 \\
12 \mathrm{p} . \\
5 \mathrm{p} . \\
4 \mathrm{p} .\end{aligned}$ & $\begin{array}{l}455 \\
350 \\
325 \\
443 \\
290 \\
330 \\
328 \\
267 \\
515 \\
380 \\
756 \\
460 \\
480 \\
262 \\
410 \\
326 \\
400 \\
342 \\
440 \\
321\end{array}$ & $\begin{array}{l}2 \cdot 3 \\
2 \cdot 1 \\
2 \cdot 0 \\
1 \cdot 0 \\
4 \cdot 1 \\
2 \cdot 5 \\
3 \cdot 0 \\
4 \cdot 7 \\
3 \cdot 3 \\
4 \cdot 7 \\
0 \cdot 86 \\
4 \cdot 5 \\
0 \\
0 \\
5 \cdot 0 \\
6 \cdot 8 \\
4 \cdot 5 \\
3 \cdot 0 \\
0 \\
2 \cdot 9\end{array}$ & $\begin{array}{cl}++ & \rightarrow 0 \\
+ & \rightarrow 0 \\
0 \rightarrow 0 \\
0 \rightarrow++ \\
+\rightarrow+0 \\
0 \rightarrow 0 \\
++\rightarrow 0 \\
0 \rightarrow 0 \\
0 \rightarrow 0 \\
+\rightarrow 0 \\
++\rightarrow+ \\
+++\rightarrow+ \\
++\rightarrow+ \\
+\rightarrow 0 \\
+\rightarrow 0 \\
+\rightarrow 0 \\
+\rightarrow 0 \\
+\rightarrow 0 \\
+\rightarrow 0 \\
0 \rightarrow 0 \\
+\rightarrow 0\end{array}$ & $\begin{array}{c}0 \rightarrow 0 \\
0 \rightarrow 0 \\
0 \rightarrow 0 \\
0 \rightarrow 0 \\
0 \rightarrow 0 \\
0 \rightarrow 0 \\
0 \rightarrow 0 \\
0 \rightarrow 0 \\
0 \rightarrow 0 \\
0 \rightarrow 0 \\
0 \rightarrow 0 \\
++\rightarrow+++++++ \\
++\rightarrow+ \\
0 \rightarrow 0 \\
0 \rightarrow 0 \\
0 \rightarrow 0 \\
0 \rightarrow 0 \\
0 \rightarrow 0 \\
0 \rightarrow 0 \\
0 \rightarrow 0 \\
0 \rightarrow 0\end{array}$ \\
\hline
\end{tabular}

\section{Methods}

\section{Assessment of Neuropathy}

During the initial clinical assessment each patient was questioned specifically for symptoms of peripheral neuropathy (except Case 11, who was semicomatose) and a full neurological examination performed. After the commencement of dialysis therapy clinical assessment was made fortnightly. The following arbitrary system has been used to grade the peripheral neuropathy : $0=$ no clinical evidence of neuropathy $;+=$ slight to moderate clinical involvement; $++=$ more severe clinical involvement $;+++=$ severe motor and sensory neuropathy.

Motor-nerve conduction was measured in the median and lateral popliteal nerves, recording from the abductor pollicis brevis and extensor digitorum brevis muscles respectively by the method described by Thomas, Sears, and Gilliatt (1959). Skin temperature over the distal part of the limb was measured immediately before the recordings were made; if it was below $32^{\circ} \mathrm{C}$. the limb was heated by immersion in warm water. Skin temperatures over the distal part of the limb at the time of recording ranged between 32 and $34.5^{\circ} \mathrm{C}$. Sensory-nerve action potentials were recorded from the median nerve at the wrist on stimulation of the index finger with ring electrodes (Gilliatt and Sears, 1958).

\section{Dialysis}

Haemodialysis was performed with a modified two-layered Kiil dialyser, using Cuprophan membrane, with the dialysate temperature kept at $40^{\circ}$ C., using single-pass dialysate (Shaldon, 1965). The duration of haemodialysis was two 14-hour periods weekly. Peritoneal dialysis was performed without an indwelling button by multiple puncture (Boen et al., 1964). The duration of dialysis was 20-24 hours weekly.

\section{Results}

\section{Clinical Findings}

These have been summarized in Table II. Before treatment sensory involvement was present in 15 patients, and consisted in pain, tingling, cutaneous hyperaesthesia and numbness, and "burning feet." The symptoms were bilateral, and maximal in the distal parts of the limbs. The lower limbs were affected earlier and more severely, although in some patients symptoms appeared simultaneously in the hands and feet. Motor involvement was present in two patients.

Reduction or loss of reflexes, usually in the lower limbs, was the commonest finding on examination, and was observed in all patients with sensory symptoms. Distal cutaneous sensory impairment in the limbs and impaired vibration sense were recorded in eight patients. In two of these impairment was only of a minor degree. In the two cases with motor involvement there was distal muscle-weakness and wasting in the limbs, and this was severe in Case 11. The clinical features of the neuropathy closely resembled the previous descriptions of uraemic neuropathy (Asbury et al., 1963).

Before the start of dialysis therapy only five patients had no clinical evidence of neuropathy. No patient developed symptoms for the first time after dialysis therapy was begun. In two patients (Cases 4 and 11) the symptoms worsened initially after starting treatment but subsequently improved, Case 4 losing all symptoms and Case 11 returning to the pretherapy status. Alterations in the state of the neuropathy after dialysis has been indicated by the arrows in Table II.

At present only three patients (Cases 10, 11, and 12) have clinical evidence of neuropathy, with persisting numbness in the toes and soles of the feet, loss of reflexes, and, in Cases 11 and 12, distal muscle-weakness and wasting. The most severe instance of neuropathy was in Case 11, who was admitted in a semicomatose state with a plasma urea of $756 \mathrm{mg} . / 100 \mathrm{ml}$. At that stage he showed generalized muscle-wasting in the limbs with loss of tendon reflexes in the legs. Sensory-testing was not possible. He was treated initially by peritoneal dialysis and subsequently by twice-weekly haemodialysis. During the two weeks after dialysis therapy was started the neurological state deteriorated with the development of severe weakness in the legs and increased weakness and loss of tendon reflexes in the arms. There was distal sensory loss in the limbs. However, after two months' treatment he was able to walk with the aid of a stick, and the tendon reflexes in the arms had returned, but he still complained of intense nocturnal burning pain in the feet. The improvement continued, and after a further two months he was able to walk unaided, and, although still having numbness of the feet, had lost the nocturnal burning pain.

\section{Nerve-conduction Studies}

An attempt was made to perform nerve-conduction studies either before or shortly after instituting dialysis. However, this was possible in only 11 patients, since a number were already receiving chronic dialysis when the nerve-conduction study was started. Of these 11 patients (Group I) $10 \mathrm{had}$ clinical evidence of peripheral neuropathy at the time the initial nerveconduction studies were performed, whereas in the remaining nine (Group II), in whom dialysis had been in progress for 6 to 22 months, there was no clinical evidence of neuropathy. The results obtained are given in Table III. 
With regard to motor-conduction velocity, the mean value (with S.D.) for the median nerve was $49.2 \pm 4.4 \mathrm{~m} . / \mathrm{sec}$. in Group I, $49.5 \pm 5.4 \mathrm{~m} . / \mathrm{sec}$. in Group II, and $49.3 \pm 4.7 \mathrm{~m} . / \mathrm{sec}$. for all patients. These values did not differ significantly from one another, but were significantly lower $(P<0.001)$ than a control group previously examined by the same technique (Thomas et al., 1959), where the mean value was $57.2 \pm 4.2$ $\mathrm{m}$./sec. In the lateral popliteal nerve the corresponding values for Groups I and II and the total results were $37.9 \pm 7.4$, $41.2 \pm 7.2$, and $39.5 \pm 7.2 \mathrm{~m} . / \mathrm{sec}$. respectively. These were again significantly lower $(P<0.001)$ than the value for the same control group, which was $49.7 \pm 7.1 \mathrm{~m}$. $/ \mathrm{sec}$. Although the mean value for Group II was slightly higher than Group I the difference did not reach the level of statistical significance. These results have been displayed as a histogram (see Chart).

\begin{tabular}{|c|c|c|c|c|}
\hline \multirow[b]{2}{*}{ Case No. } & \multicolumn{2}{|c|}{$\begin{array}{l}\text { Motor-nerve Conduction } \\
\text { Velocity } \mathrm{m} . / \mathrm{sec} \text {. }\end{array}$} & \multicolumn{2}{|c|}{ Sensory-nerve Action Potentials } \\
\hline & Median & $\begin{array}{l}\text { Lat. } \\
\text { Popliteal }\end{array}$ & $\begin{array}{c}\text { Finger/Wrist } \\
\text { Latency } \\
\text { (msec.) }\end{array}$ & $\underset{(\mu \mathrm{V})}{\text { Amplitude }}$ \\
\hline \multicolumn{5}{|c|}{ Patients Examined before Start of Dialysis. Group I } \\
\hline $\begin{array}{l}9 \\
10 \\
11 \\
12 \\
13 \\
14 \\
15 \\
16 \\
17 \\
19 \\
20\end{array}$ & \begin{tabular}{|l}
54 \\
54 \\
41 \\
50 \\
49 \\
44 \\
46 \\
54 \\
53 \\
50 \\
48
\end{tabular} & $\begin{array}{l}38 \\
40 \\
34 \\
- \\
40 \\
33 \\
32 \\
55 \\
36 \\
30 \\
41\end{array}$ & $\begin{array}{c}3.5 \\
* \\
\dagger \\
\dagger \\
3 \cdot 2 \\
4 \cdot 3 \\
* \\
4 \cdot 0 \\
3 \cdot 5 \\
4 \cdot 0 \\
3.5\end{array}$ & $\begin{array}{r}5 \\
* \\
+ \\
t \\
8 \\
10 \\
* \\
12 \\
16 \\
17 \\
15\end{array}$ \\
\hline \multicolumn{4}{|c|}{ Patients First Examined 6-22 Months after Starting Dialysis } & Group II \\
\hline $\begin{array}{r}1 \\
2 \\
3 \\
4 \\
5 \\
6 \\
7 \\
8 \\
18\end{array}$ & \begin{tabular}{|l|l|}
51 \\
56 \\
54 \\
54 \\
46 \\
51 \\
42 \\
50 \\
41
\end{tabular} & $\begin{array}{l}33 \\
49 \\
41 \\
51 \\
34 \\
44 \\
48 \\
38 \\
33\end{array}$ & $\begin{array}{c}4.0 \\
3.5 \\
3.5 \\
3.2 \\
3.5 \\
3.5 \\
3.5 \\
* \\
+\end{array}$ & $\begin{array}{r}12 \\
12 \\
8 \\
11 \\
5 \\
10 \\
8 \\
* \\
+\end{array}$ \\
\hline
\end{tabular}

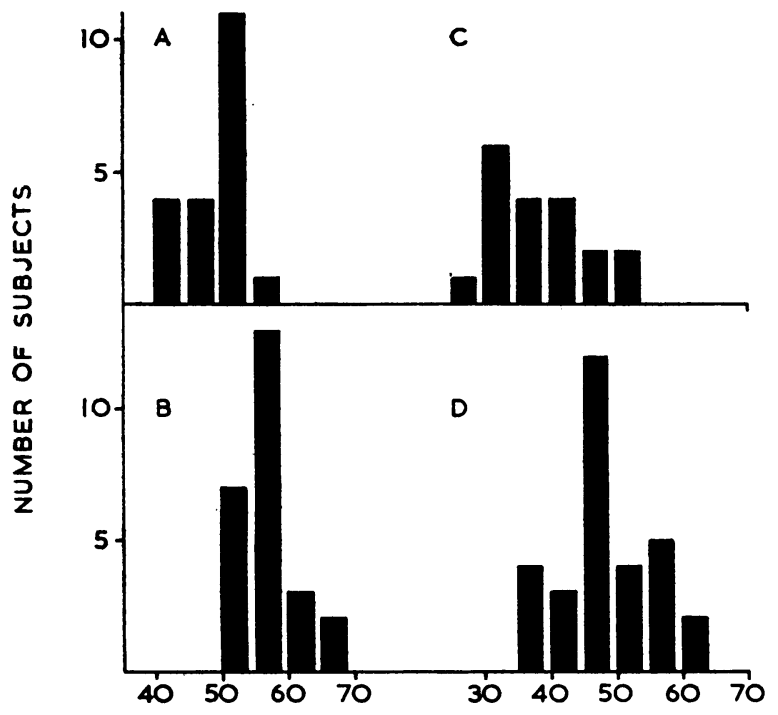

CONDUCTION VELOCITY $(\mathrm{m} . / \mathrm{sec}$.)

Distribution of motor-nerve conduction velocity for the median (A and B) and lateral popliteal (C and D) nerves for uraemic (A and C) and control (B and D) subjects. Control observations taken from Thomas et al. (1959).

Recordings of sensory-nerve conduction in the median nerve at the wrist on stimulating the digital nerves in the index finger were made in 17 patients. Using a similar technique, Gilliatt and Sears (1958) found in a series of control subjects that the amplitude of the potential varied from 9 to $45 \mu \mathrm{V}$ and the latency from 2.5 to $4 \mathrm{msec}$. In three of our patients no action potential was recorded, and in five the amplitude was below the lower limit of the normal range. The values for the latency of the potential fell within the upper part of the normal range in the majority of the patients, but exceeded the upper limit of normal in only one case (Case 14). In general there was a good correlation between the results of the motorand sensory-nerve conduction studies.

\section{Discussion}

It has been suggested that earlier commencement of adequate dialysis therapy in patients with end-stage renal failure may prevent the development of peripheral neuropathy, or reverse such clinical neuropathy as was present before therapy was started (Hegstrom et al., 1961, 1962 ; Lindholm et al., 1963 ; Versaci et al., 1964 ; Shaldon, 1965). The present communication on the results in 20 patients, representing 17 patient-years of dialysis therapy, supports this view. However, emphasis must be placed on the use of early and adequate dialysis therapy. It seems likely that failure to improve neuropathy is due to inadequate dialysis, and the appearance of neuropathy or worsening of the condition after the start of therapy should be regarded as an indication for intensive treatment. The underlying cause of the neuropathy remains obscure. It is not influenced by massive vitamin supplementation (Shaldon, 1963).

The slowing of nerve conduction found in the patients reported in this paper and in other studies on uraemic neuropathy (for example, Preswick and Jeremy, 1964) is relatively mild. The magnitude is such that it could be explained by the loss of faster conducting fibres, and does not necessarily imply a disturbance of the conducting mechanism (Thomas et al., 1959). The more severe degrees of slowing of conduction that may be seen in neuropathies in which segmental demyelination occurs have not been encountered. The post-mortem pathological changes in uraemic neuropathy consist of a destruction of myelinated nerve fibres involving both axons and myelin (Asbury et al., 1963). These changes were associated with chromatolysis of anterior horn cells of the type seen with axonal injury. Recovery of nerve conduction after such a process is likely to be slow, and this is being assessed by serial observations on the patients reported in this communication. The relatively rapid improvement or disappearance of neuropathy in most of our patients is so far unexpected.

\section{Summary}

Fifteen out of twenty patients suffering from end-stage chronic renal failure were found to have clinical evidence of peripheral neuropathy before the start of chronic dialysis treatment. Electrophysiological studies revealed abnormalities of motor- and sensory-nerve conduction in these patients. With adequate dialysis complete disappearance of symptoms occurred in all but three of the affected patients. The value of early and adequate dialysis in the treatment of the peripheral neuropathy of chronic uraemia is stressed.

ADDENDUM.-Since this paper was submitted a further report on neuropathy in chronic renal failure has appeared (Tenckhoff, H. A., Boen, F. T., Jebsen, R. H., and Spiegler, J. H. (1965), ๆ. Amer. med. Ass., 192, 1121).

\section{REFERENCES}

Asbury, A. K., Victor, M., and Adams, R. D. (1963). Arch. Neurol. (Chic.), 8, 413 .

Barber, N.' D., Nakamoto, S., McCormack, L. J., and Kolff, W. J. (1963). Trans. Amer. Soc. artif. intern. Organs, 9, 21.

Boen, S. T. (1964). In Acute Renal Failure: A Symposium, p. 124, edited by S. Shaldon and G. C. Cook. Blackwell, Oxford.

Burnell, J. M.., Murray, J. S., Scribner, B. J., and Hegstrom, R. M (1963). West European Symposia on Clinical Chemistry ; "Water and Electrolyte Metabolism," II, p. 237. Amsterdam.

Funck-Brentano, J. L., and Vantelon, J. (1963). Excerpta Medica,

Gilliatt, R. W., and Sears, T. A. (1958). ₹. Neurol. Neurosurg. Psychiat., 
Gonzales, F. M., Pabico, R. C., Brown, H. W., Maher, J. F., and Schreiner, G. E. (1963). Trans. Amer. Soc. artif. intern. Organs, 9, 11.

Hegstrom, R. M., Murray, J. S., Pendras, J. P., Burnell, J. M., and Scribner, B. H. (1961). Ibid., 7, 136.

Murray, J. S., Pendras, J. P., Burnell, J. M., and Scribner, B. H. (1962). Ibid., 8, 266.

Lindholm, D. D., Burnell, J. M., and Murray, J. S. (1963). Ibid., 9,

Locke, S., Merrill, J. P., and Tyler, H. R. (1961). Arch. intern. Med., 108, 519.

Murray, J. S., Pendras, J. P., Lindholm, D. D., and Erickson, R. V. (1964). Trans. Amer. Soc. artif. intern. Organs, 10, 191.

\title{
Plasma Renin Concentration in Human Hypertension II : Renin in Relation to Aetiology
}

\author{
J. J. BROWN,* M.B., B.S., B.SC., M.R.C.P. ; D. L. DAVIES,* M.B., B.S. ; \\ A. F. LEVER,* M.B., B.S., B.SC., M.R.C.P. ; J. I. S. ROBERTSON,* M.B., B.S., B.SC., M.R.C.P.
}

Brit. med. F., 1965, 2, 1215-1219

In previous papers (Brown et al., 1965a, 1965b) we have demonstrated, in clinical hypertension, a close inverse relationship between renin concentration and plasma sodium which appears to be independent of aetiology, the height of the arterial pressure, complications, and treatment. The present communication is concerned with an analysis of renin and sodium in hypertension in relation to aetiology. The methods used in this study are as given previously (Brown et al., 1965b, 1965d) ; data on additional cases have been included, but the series is basically that described earlier. Plasma renin concentrations in a total of 276 hypertensive patients have been compared with those in 125 normal subjects having a mean renin concentration of 8.2 ; S.D. 2.7 units/1. (Brown et al., 1964d).

\section{Overactivity of the Adrenal Cortex}

\section{Primary Aldosteronism due to Adrenal Tumour}

In this condition hypertension is caused by an aldosteronesecreting adrenal cortical adenoma (Conn, 1955 ; Mader and Iseri, 1955 ; Milne et al., 1957 ; Conn et al., 1964b). Plasma sodium and total exchangeable sodium are often raised, while potassium is low. Whether all the features of the syndrome can be attributed solely to the excess aldosterone, or whether other hormones produced by the tumour are necessary, has been the subject of discussion (see Ross and Hurst, 1965).

The hypertension and increased exchangeable sodium are accompained by depression of plasma renin concentration ; after removal of the tumour, with correction of the hypertension and electrolyte abnormalities, renin rises into the normal range (Brown et al., 1963b, 1964a-c, 1965d) (Fig. 1).

Alternatively, the administration of spironolactone to patients with this syndrome may correct the hypertension and electrolytes without affecting aldosterone secretion (Brown et al., 1963b, 1964a, 1964b, 1964c, 1965d) ; plasma renin concentration rises to normal as the sodium falls, emphasizing the interrelationship between renin and sodium, and showing that the effect of the adrenal overactivity on renin concentration is not a direct one but is mediated by the electrolyte abnormalities (Brown et al., 1963b, 1964a, 1964c).

Estimations of other components of the renin-angiotensin system have been handicapped by relative insensitivity, but in

* Medical Unit, St. Mary's Hospital, London.
Osler, W. (1892). The Principles and Practice of Medicine, p. 737. Apoleton, New York.

Preswick, G and Jeremy, D. (1964). Lancet, 2, 731.

Preswick, G., and (1963) West European Symposia on Clinical Chemistry:

"Water and Electrolyte Metabolism," II, p. 241. Amsterdam. (1965). Scientific Basis of Medicine, Annual Review. In press. (1965). Scientific Basis of Medicine, Annual Review. In press. Clinical Chemistry: "Water and Electrolyte Metabolism," II, p. 288. Amsterdam.

Thomas, P. K., Sears, T. A., and Gilliatt, R. W. (1959). F. Neurol. Neurosurg.' Psychiat., 22, 175.

Versaci, A. A., Olsen, K. J., McMain, P. B., Nakamoto, S., and Kolff, W. J. (1964). Trans. Amer. Soc. artif. intern. Organs, 10, 328. several cases have given results in general agreement with these measurements of renin concentration. Thus circulating angiotensin has usually, though not invariably, been undetectable in primary aldosteronism (Biron et al., 1962 ; Morris et al., 1964).

Measurements of " renin activity" 1 have been less consistent. Thus Yoshinaga et al. (1963), who used a modification of the method of Helmer and Judson (1963), reported high normal levels in this disease. Kirkendall et al. (1964), with a basically similar technique, found plasma "renin activity" variously low or undetectable before

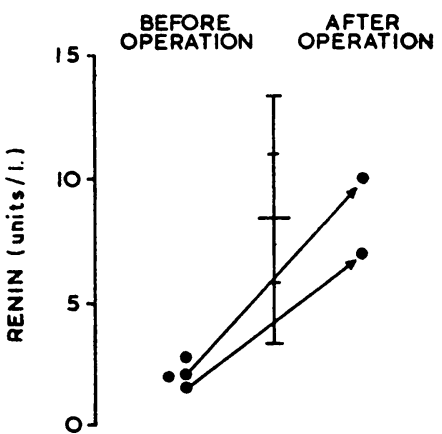

FIG. 1.-Plasma renin concentrations before operation in four patients from whom aldosterone-producing tumours were later removed. Post-operation values also shown in two. Normal mean $t 1$ and 2 S.D. indicated. primary aldosteronism, the values rising after removal of the tumour. Findings similar to those of Kirkendall et al. (1964), but with an occasional result well in the measurable range before operation, were later published by Conn et al. (1964a), who used the extraction procedure of Boucher et al. (1964).

Thus, while these tests may sometimes add support to the preoperative diagnosis of primary aldosteronism, the limits of their reliability are uncertain. In the patients we have studied renin concentration and plasma sodium have appeared closely linked. Sodium values are not given in the case reports of Biron et al. (1962), Yoshinaga et al. (1963), Conn et al. (1964a), Kirkendall et al. (1964), and Morris et al. (1964), and it therefore remains uncertain whether estimations of renin concentration, renin activity, or angiotensin are capable of providing diagnostic information which cannot be inferred from repeated and accurate measurement of plasma and exchangeable sodium. Leutscher (1964) refers to cases of primary aldosteronism with persistently normal sodium, but we have not so far encountered one. Renin measurements in such patients would be of considerable theoretical and practical interest.

The meaning of this term has been discussed previously (Brown et al., 1965b). 